\title{
A Descriptive Cross-Sectional Study on the Assessment of Public Knowledge, Attitude and Perception on Medication Errors
}

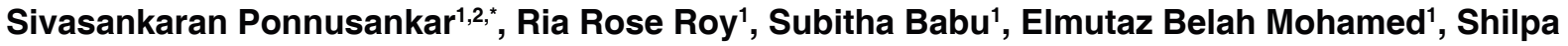 \\ Cyril $^{1}$, Mohamed Kamal ${ }^{1}$
}

${ }^{1}$ Department of Pharmacy Practice, JSS College of Pharmacy, Udhagamandalam - 643 001. The Nilgiris. Tamil Nadu, INDIA. 2JSS Academy of Higher Education and Research, Mysuru, Karnataka, INDIA

\begin{abstract}
Background: Medication errors could lead to various problems which include decreased therapeutic efficacy, added workload and financial burden, litigation problems and most importantly toxic effects in patients. Studies have revealed that people have more negative perceptions when medical mishaps lead to severe health concerns. Aim and Objectives: The aim of the study is to assess the perception, knowledge, and attitude of medication errors among the general population. The objectives are to examine the public knowledge and perceived reaction to medication errors. Moreover, to study the general public attitude towards medication errors and accordingly, to create an awareness about medication errors. Methodology: A descriptive cross-sectional survey with a pretested questionnaire. Results: Among 500 respondents who participated in the study, 275 of them were female (55\%) and 225 of them were male $(45 \%)$. About $68.2 \%$ of the respondents had not heard of medication errors. Female respondents and young adults aged between 21-30 years had a better level of knowledge, perception, and attitude towards medication errors. Respondents above 61 years of age had the least level of knowledge about medication errors. A total of $66.6 \%$ of the respondents were under an impression that physicians were the only people who were contributing the maximum toward the incidence of medication errors. With regard to the action to be taken when medication error occurs, $54.2 \%$ of the respondents had the opinion for opting legal claim. People from Kerala had better level of knowledge and attitude whereas people from Tamil Nadu had a better perception of medication errors. Conclusion: This study reported that the general public agreed medication errors pose serious threat to people's lives. Furthermore, majority of the respondents suggested that medication errors reporting system should be established in India. However, an educational intervention program and computer aided prescribing order entry can contribute to the lowering of such errors.
\end{abstract}

Key words: Medication errors, Knowledge, Attitude, Perception, General public, Causes of medication errors, Reporting of medication errors.

\section{INTRODUCTION}

Medication errors are events that are posing a serious threat to the society currently. It may lead to an inappropriate medication use or patient harm. ${ }^{1}$ The medication errors could lead to various problems which include decreased therapeutic efficacy, added workload and financial burden, litigation problems and most importantly toxic effects in patients. Hence, reasons or factors relating to these errors should be ruled out in order to bring up a successful treatment process as well as to reduce the harm caused to the patient.

Previously conducted studies state that, irrational and inappropriate prescribing of
DOI: 10.5530/ijopp.10.4.57

Address for correspondence: Dr. Sivasankaran Ponnusankar,

Professor and Head, Department of Pharmacy Practice, JSS College of Pharmacy, Rocklands, Udhagamandalam- 643001, The Nilgiris, Tamil Nadu, INDIA. Phone no: +91 9489613428 Email Id: ponnusankarsivas@ gmail.com

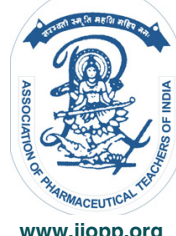


the drugs was the main reason for making the prescribing errors as most commonly occurring errors. ${ }^{2,3,4}$ In a study conducted in England, majority of the incidences of medication errors were reported from secondary care setups which indicated that such incidences were predicated common in primary healthcare set-ups but often left unreported. ${ }^{5,6}$ In another study conducted in the United States of America, prescriptions were the major focus and no other factors were considered while studying the cause of medication errors. ${ }^{7}$ Moreover, a study conducted in Netherland reported that $60 \%$ of over 7200 medication orders contained at least one prescribing fault and that there were 103 likely preventable adverse events. The medication errors that were rarely seen and reported mostly included a failure to note contraindications, allergies, failure to recognize drug-drug interactions, and wrong choice of drug therapy. ${ }^{8}$ Internationally, there are ample numbers of studies that have been conducted with their main focus on medication errors though that had not been sufficiently studied in the Indian scenario. ${ }^{9,10,11,12,13,14,15}$ However, there are only a very few studies that have been conducted in India out of which one study conducted in Delhi focused on the prescribing patterns and the errors associated with the prescription. ${ }^{12}$ On the other hand, a study conducted in Kerala targeted the types of errors that commonly occurred at the study site (a tertiary care hospital). ${ }^{13}$

Hence, to fulfill the clinical practice gap, this study was conducted with the aim at assessing the knowledge, perception, and attitude of the general public on medication errors. Furthermore, as previously illustrated, there are not many studies conducted in India regarding this topic and the ones that have been conducted focused more on the health care providers and inpatients setup. Therefore, this study has a broader perspective and reaches out to the general public to create better knowledge, perception, and attitude towards medication errors among the general public based on the assessments so that the occurrence could be prevented in an effective manner before any further mishaps happen.

\section{METHODS}

It is a descriptive cross-sectional survey using a pretested structured questionnaire to collect data from the public of Tamil Nadu, Delhi, and Kerala. Totally 500 participants completed the questionnaire during six month study period (November 2015 - April 2016). The study protocol was approved by the Institutional Ethical Committee JSS College of Pharmacy, Udhagamandalam [Ref No: JSSCP/DPP/09/2015-16]. An oral informed consent was obtained from all the subjects before documenting their response. Age between 18 to 85 years was the inclusion criteria. Participants who unable to understand English, Tamil, Malayalam or Hindi, and unwilling to take part in the study were excluded. This study was adapted pretested structured questionnaire containing 26 questions prepared to assess the public's knowledge, perception, and attitude towards of the medication errors. All the 26 questions were categorized into four sections namely:

\section{Demographic data}

This section represents the details of the respondents like gender, age, residence place and educational level.

\section{I) Assessment of knowledge}

This included 4 questions representing the respondent's pre-acquired knowledge or any previous knew information about the term 'medication errors'.

\section{II) Assessment of perception}

This section contained 5 questions that test the understanding of the topic among the general public.

\section{III) Assessment of attitude}

This section contained 5 questions assessing how the public thought about medication errors and its consequences.

The questionnaire was validated by conducting a pilot study among 40 randomly selected respondents to assess the quality of the questionnaire, furthermore, the relevancy of the questionnaire content was verified by a committee consisting of three experts in fields of pharmacy at JSS College of Pharmacy, Udhagamandalam. There were certain changes that were made to the questionnaire which included addition of questions, changes made in the order of questions, and simplified questions. Furthermore, change and addition made in the options such as all others and do not know. Scores were allowed for each question based on the options provided and they were ranked according to the closeness to the answers that would provide the best knowledge, perception, and attitude. An Online sample size calculator (SurveyMonkey) and stratified sampling technique were used to calculate the sample sizes in the study. ${ }^{16}$ The data collected were analyzed using SPSS for Windows, version 21.0, Armonk, NY: IBM crop and the chi-square test was used to find out the differences. 


\section{RESULTS AND DISCUSSION}

A total number of 500 respondents surveyed for the study from Tamil Nadu, Kerala and Delhi. A pre-tested questionnaire was administered and the responses were collected for a period of 6 months. Out of 500 respondents who participated in the study, 275 were female $(55 \%)$ and 225 were male (45\%). Their mean ages were 37.42 years and 36.23 years respectively. The mean age of 500 respondents was 36.7 years, with 18 and 81 as minimum and maximum ages. The level of education of respondents ranged from no education to graduation. Accordingly, 67.4\% had obtained graduation, followed by those with higher secondary education $20 \%$, secondary education (6.2\%) and primary education (3\%) while $(3.4 \%)$ had received no formal education. $35 \%$ of the study population were from Kerala, followed by $32.6 \%$ from Delhi, and 32.4\% from Tamil Nadu.

\section{Assessment of public perception of medication errors}

The survey respondents (59.6\%) indicated that medication errors pose serious threats to people's lives, whereas $9 \%$ did not consider error as a threat. Almost $79.2 \%$ of the respondents reported that errors would increase their healthcare cost. The perception of respondents about cases of medication errors showed that the physicians (66.6\%) were perceived to be contributing the maximum towards the incidence of medication errors followed by nurses $(8.2 \%)$. Majority $(90.6 \%)$ of the respondents suggested that medication errors reporting system should be established in India. Overall, most of the respondents had the opinion for an opting legal claim (54.2\%) as the action to be taken in reaction to an occurrence of medication errors followed by financial compensation $(25 \%)$, taking no action $(12.8 \%)$, and reduce confidence in other healthcare providers $(8 \%)$ which shown in Table 1. the statistical results indicated that there is a significant association between perception of medication errors and age $\left(\chi^{2}=0.031 ; \mathrm{P}<0.05\right)$, level of education $\left(\chi^{2}=0.002\right.$; $P<0.05)$, and locality of residence of the respondents $\left(\chi^{2}=0.023 ; P<0.05\right)$. Also, the gender of the respondents $\left(\chi^{2}=0.468 ; P<0.05\right)$ did not significantly influence their perception of medication errors.

\section{Assessment of public knowledge on medication errors}

The analysis of the results showed that majority $(68.2 \%)$ of respondents had not heard about of medication errors. The factors that contribute to assessing the general public knowledge about causes of the medication errors in healthcare setup are shown in Table 2. It shows that more commonly the prescribing errors (32.2\%) were thought to be the leading causes of medication errors followed by dispensing (10.4\%), administration $(5.6 \%)$ and preparation $(3.2 \%)$. Around $31.4 \%$ of the respondents had an idea that all of the above-mentioned types of errors that could lead to medication errors, concluding that they had a good knowledge about the causes of medication errors. Majority (87.8\%) of respondents were interested in knowing about medication errors. Almost $49.2 \%$ of the respondents considered medication errors to be a preventable event. Ultimately, respondents also indicated that physicians (57.6\%) were the only people to whom they could report medication errors followed by pharmacists $(28.4 \%)$ and nurses $(5.6 \%)$. However, few of the respondents $(12.4 \%)$ had an experience of adverse drug reactions. Markedly, the statistical results showed that there is a high significant association between knowledge of medication errors and gender $\left(\chi^{2}=0.007 ; P<0.05\right)$, level of education $\left(\chi^{2}=0.002\right.$; $P<0.05)$, and locality of residence $\left(\chi^{2}=0.001 ; P<0.05\right)$ of the respondents. Whereas, the age of the respondents $\left(\chi^{2}=0.468 ; P<0.05\right)$ less significantly influence their knowledge of the medication errors.

\section{Assessment of public's attitude to medication errors}

Most common mistakes the respondents commit while taking medications were the forgetfulness of taking medications $(32.2 \%)$ and a few $(6.6 \%)$ don't finish the prescribed course of drugs. Majority, (94.2\%) of respondents had not reported any medication errors yet presented in Table 3. Predominately the statistical analysis showed that there is a high significant association between attitude towards medication errors and locality of residence $\left(\chi^{2}=0.001 ; P<0.05\right)$. However, the age $\left(\chi^{2}=0.796 ; P<0.05\right)$, level of education $\left(\chi^{2}=0.925\right.$; $P<0.05)$, and gender $\left(\chi^{2}=0.559 ; P<0.05\right)$ of the respondents did not significantly influence their attitude towards medication errors.

Overall, the study aimed at assessing public's knowledge, perception, and attitude of medication errors, even though medication errors have serious implications for the public safety. Majority of respondents were interested in knowing about medication errors which were fulfilled by administering a leaflet containing all the necessary information for lighting-on knowledge toward medications errors. The highest proportion of respondents in this study were interested in taking a legal action against the people who committed the error. This study also found that prescribing errors were thought to be the leading causes of medication errors and that the public seemed to have negative reactions toward medication errors if the errors were detected by 
Table 1: Factors assessing public perception on medication errors.

Questions that assessed respondents perception on medication errors

Can medication errors harm you?

Options

No

Do not know

Yes

No

According to you, medication errors are caused by:

Would you like medication errors reporting system to come into practice within the public?

Opinion on the actions to be taken in reaction to medication errors:

\begin{tabular}{cc} 
Yes & 298 \\
No & 45 \\
Do not know & 157 \\
Yes & 396 \\
No & 104 \\
Physicians & 333 \\
Nurses & 41 \\
Others & 126 \\
Yes & 453 \\
No & 47 \\
Legal claim & $\mathbf{2 7 1}$ \\
Financial compensation & 125 \\
Taking no action & 64 \\
Reduce confidence in other healthcare providers & 40 \\
\hline
\end{tabular}

Table 2: Factors assessing public knowledge on medication errors.

\section{Questions that assessed respondents knowledge on medication errors}

\begin{tabular}{|c|c|c|}
\hline \multirow[t]{2}{*}{ Have you heard about medication errors? } & Yes & 159 \\
\hline & No & 341 \\
\hline \multirow[t]{8}{*}{ Perceived causes of medication errors: } & Prescribing & 161 \\
\hline & Dispensing & 52 \\
\hline & Administration & 28 \\
\hline & Preparation & 16 \\
\hline & None & 16 \\
\hline & All of the above & 157 \\
\hline & Do not know & 67 \\
\hline & Others & 3 \\
\hline \multirow[t]{2}{*}{ Are you interested in knowing about medication errors? } & Yes & 439 \\
\hline & No & 61 \\
\hline \multirow[t]{3}{*}{ Are medication errors avoidable? } & Yes & 246 \\
\hline & No & 49 \\
\hline & Do not know & 205 \\
\hline \multirow[t]{4}{*}{ Whom do you report about medication errors? } & Physician & 288 \\
\hline & Pharmacist & 142 \\
\hline & Nurse & 28 \\
\hline & Others & 42 \\
\hline \multirow[t]{2}{*}{ Have you come across any adverse drug reaction? } & Yes & 62 \\
\hline & No & 438 \\
\hline
\end{tabular}

themselves. The findings of statistical analysis showed the association of the age, gender, level of education and locality of residence with knowledge, perception, and attitude of medication errors. It was found that young adults aged between 21-30 years, female and graduates had a better level of knowledge, attitude, and perception of medication errors. Respondents above 61 years of age Indian Journal of Pharmacy Practice, Vol 10, Issue 4, Oct-Dec, 2017 had the least level of knowledge whereas respondents aged less than 20 years had the least level of perception about medication errors. People of Kerala had a better level of knowledge and attitude of medication errors whereas people of Tamil Nadu had a better perception of medication errors. 
Table 3: Factors assessing public's attitude toward medication errors.

Questions that assessed respondents attitude toward medication errors

Can you report medication errors?

Mistakes you commit while taking medications?

Have you reported any medication errors?

\section{Options}

Yes

No

Do not know

Taking the medication at the wrong time

Inappropriate way of administering the drugs

Taking the drugs at the wrong dose

Don't finish the prescribed course of drugs

Not taking the drug even though prescribed

Forgot to take the drugs

Others

Nil

Yes

No
Number of respondents

211

55

234

130

29

40

33

57

161

49

1

29

471

\section{CONCLUSION}

Medication errors still remain the main concern of the healthcare system. Therefore, it is important to enhance the understanding of general public about the causes, complications, and proper action toward medication errors. Predominantly, establishing an effective and a reliable medication errors reporting system is needed in minimizing such events. Hence, the adaption of information technology in prescribing, labeling and dispensing of medicines is needed to identify and prevent an occurrence of medication errors. In-addition to that, educational intervention programs for general public are exigency.Also the healthcare professionals should abide by their responsibilities in a much more effective and careful manner to avoid errors. Perhaps clinical pharmacists could play a crucial role in the disclosure of the event.

\section{ACKNOWLEDGEMENT}

The authors wish to thank Tamil Nadu Pharmaceutical Sciences Welfare Trust, Chennai for their student research scholarship support for this work.

\section{CONFLICT OF INTEREST}

The authors report no conflict of interest.

\section{FINANCIAL SUPPORT}

Support received from TamilNadu Pharmaceutical Sciences Welfare Trust, Chennai as Student Research Scholarship (TNPSWT:2015/2456 Dated: $23^{\text {rd }}$ November 2015).

\section{REFERENCES}

1. Medication Errors Related to Drugs. [updated 2016 Aug 7; cited 2016 Nov 9]. Available from:https://www.fda.gov/drugs/drugsafety/medicationerrors/Fda.gov [Internet].

2. Kozer E, Scolnik D, Macpherson A, Keays T, Shi K, Luk T, et al. Variables associated with medication errors in pediatric emergency medicine. Pediatrics.2002; 110(4):737-42.

3. Lesar TS, Lomaestro BM, Pohl H.Medication-prescribing errors in a teaching hospital. A 9-year experience. Arch Intern Med.1997;157(14):1569-76.

4. Ghaleb MA, Barber N, Franklin BD, Yeung VW, Khaki ZF, Wong IC. Systematic review of medication errors in pediatric patients. Ann Pharmacother.2006;40(10):1766-76.

5. Barber ND, Dean BS. The incidence of medication errors and ways to reduce them. Clin Risk.1998;4(4):103-6.

6. Leape LL, Bates DW, Cullen DJ, Cooper J, Demonaco HJ, Gallivan T, et al. Systems analysis of adverse drug events. ADE Prevention Study Group. JAMA.1995;274(1):35-43.

7. Devine EB, Wilson-Norton JL, Lawless NM, Hansen RN, Hazlet TK, Kelly K, et al. Characterization of prescribing errors in an internal medicine clinic. Am J Health Syst Pharm.2007;64(10):1062-70.

8. Doormaal JE, Van den Bemt PM, Mol PG, Zaal RJ, Egberts AC, HaaijerRuskamp FM,et al. Medication errors: the impact of prescribing and transcribing errors on preventable harm in hospitalized patients. Qual Saf Health Care.2009;18(1):22-7.

9. Ushie BA, Salami KK, Jegede AS, Oyetunde M.Patients' knowledge and perceived reactions to medical errors in a tertiary health facility in Nigeria. Afr Health Sci.2013;13(3):820-8.

10. Ibrahim GA, Wail AH, Dareen MH. A five years retrospective study of reported medication incidents at a Jordanian teaching hospital: patterns and trends. Int. J.Hum Soc Sci.2014;4(5):1-8.

11. Jolly Johnson, Merlin Thomas. Medication errors: knowledge and attitude of nurses in Ajman, UAE. Gulf Med J.2013;1(S1):S143-7.

12. Samsiah A, Othman N, Jamshed S, Hassali MA. Perceptions and attitudes towards medication errors reporting in primary care clinics: A qualitative study in Malaysia PLoS One.2016;11(12):e0166114.

13. You MA, Choe MH, Park GO, Kim SH, Son YJ. Perceptions regarding medication administration errors among hospital staff nurses of South Korea. Int J Qual Health Care.2015;27(4):276-83.

14. Anurag J, Bhatia MS, Srivastava S.Medication errors in Clinical Practice. Delhi Psy J.2011;14(2):205-10.

15. Karthikeyan M, Lalitha D. A prospective observational study of medication errors in general medicine department in a tertiary care hospital. Drug Metabol Drug Interact.2013;28(1):13-21.

16. SurveyMonkey [Internet]. Sample Size Calculator: Understanding Sample Sizes. 2015. Available from: https://www.surveymonkey.com/mp/sample-sizecalculator/.

Indian Journal of Pharmacy Practice, Vol 10, Issue 4, Oct-Dec, 2017 